\title{
LA SCIENCIA THEORICA SPECULATIVA EN LA CONSTRUCCIÓN GÓTICA. EL PROMOTOR ECLESIÁSTICO DE LA CATEDRAL MEDIEVAL
}

\author{
POR \\ JOSEP LLUIS I GINOVART \\ Universitat Rovira i Virgili
}

\section{RESUMEN}

La construcción de las catedrales góticas puede considerarse como un trasvase de conocimiento entre las figuras eclesiásticas del obispo y Capítulo, y el arquitecto medieval. La belleza de la catedral dependía de la practica del constructor medieval, y de la teorica de sus promotores. Una muestra de esta transversalidad es el ejemplo de la construcción de la catedral de Tortosa. La metrología y la proporción de la arquitectura de la catedral, emanan directamente de las fuentes filosóficas del orden gótico. Los principales autores de referencia están identificados en su biblioteca capitular: San Agustín (ACTo 20), Calcidio y Capella (ACTo $n^{\circ}$ 80) y Macrobio (ACTo 236). Esta circunstancia ha permitido establecer unos puntos de contacto entre los saberes del promotor y del constructor góticos.

\section{PALABRAS CLAVE}

Catedral gótica; Capítulo; neoplatonismo; San Agustín; Calcidio; Capella Macrobio; Tortosa. 


\section{THE SCIENCIA THEORICA SPECULATIVA IN GOTHIC CONSTRUCTION. THE CHURCH PROMOTER MEDIEVAL CATHEDRAL}

\section{ABSTRACT}

The construction of Gothic cathedrals can be seen as a transfer of knowledge between ecclesiastical figures the bishop and Chapter, and medieval architect. The beauty of the cathedral depended on the practica of medieval mason, versus the teorica of the church promoter. An example of this is the example of mainstreaming, the one of the construction of the Cathedral of Tortosa. Metrology and proportion of the architecture of the cathedral, derived directly from the philosophical sources of the Gothic order. The main authors of reference are identified in the chapter library; Augustine ACTo 20, Calcidius and Capella ACTo $n^{\circ}$ 80, Macrobius ACTo 236. This has allowed us to establish contact points between knowledge of the promoter and the gothic builder.

\section{KEY WORDS}

Gothic cathedral; Chapter; Neoplatonism; Augustine; Calcidius; Capella; Macrobius; Tortosa.

$\begin{array}{lr}\text { Recibido/Received } & 23-09-2013 \\ \text { Aceptado/Accepted } & 13-05-2014\end{array}$

Las figuras eclesiásticas del obispo y Capítulo, junto con el arquitecto medieval, engendran, en el ilusionario agustiniano, la catedral como la ciudad de Dios construida por los hombres (Figura 1). La catedral gótica de Tortosa fue promovida en 1345, y construida a partir de 1377. En ella es posible relacionar el conocimiento de los promotores eclesiásticos con el de los maestros medievales. La interacción entre ambos saberes es imprescindible para la construcción de estos edificios, ${ }^{1}$ y su estudio se establece a partir de la fábrica construida y los códices de su Archivo Capitular (ACTo.). ${ }^{2}$

1 El International Catalogue of Mediaeval Scientific Manuscripts del Institute for the History of Science de la Universidad de Munich y el Max Planck Institute for the History of Science de Berlin atribuye la existencia de 30.00035.000 códices en Europa occidental, (500-1500) de los que 80 pertenecen al ACTO.

2 La actual catalogación según, Bayerri, E. 1962. Los Códices Medievales de la Catedral de Tortosa. Novísimo inventario descriptivo. Tortosa: Talleres Gráficos Algueró y Baiges. Los manuscritos existentes en el inico de la construcción de la catedral gótica, Baiges, I. 1999. Els manuscrits de la catedral 
Figura1

CLAVE NAVE CENTRAL CATEDRAL TORTOSA. SAN AGUSTÍN (1494)

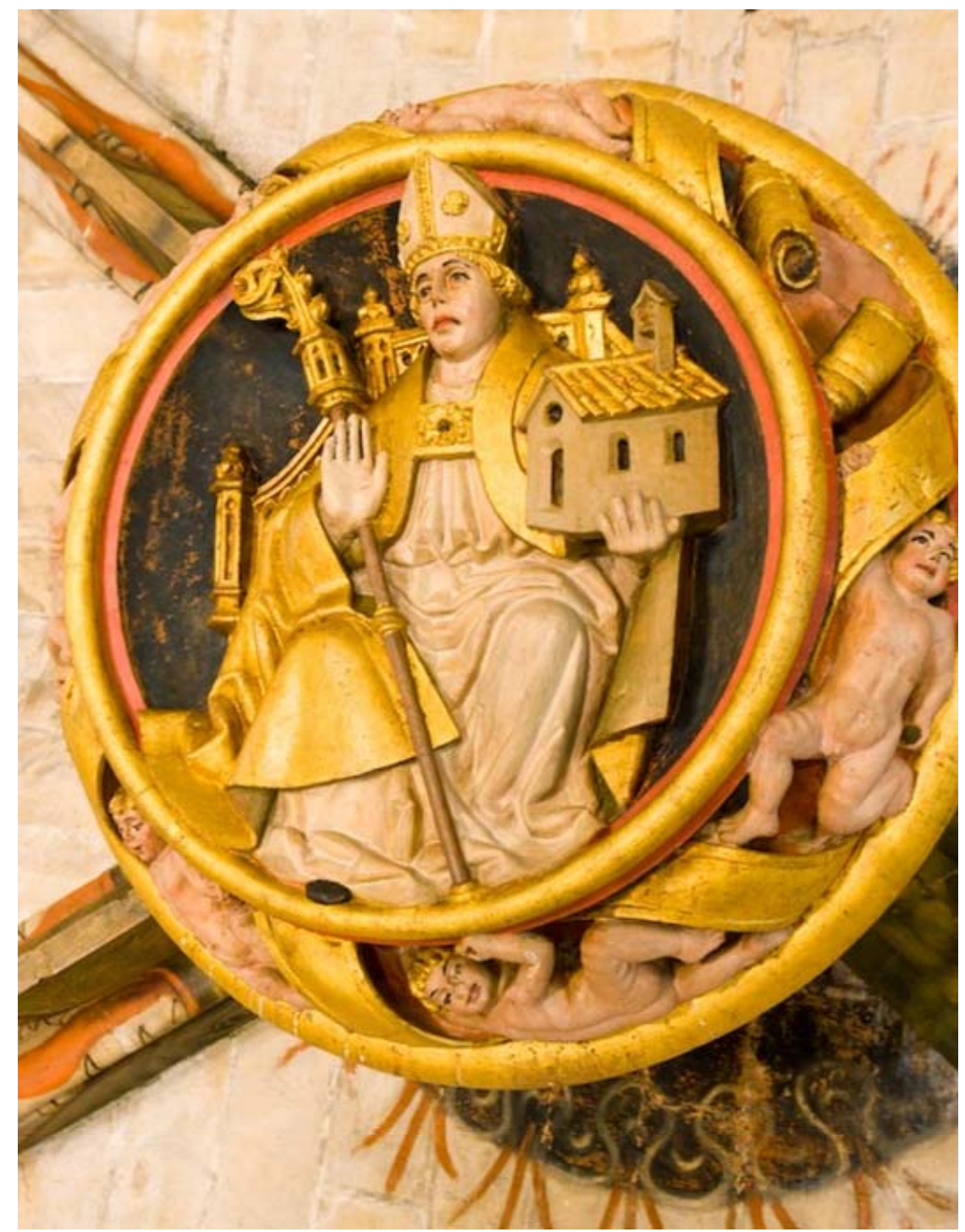

El objetivo de la investigación es determinar cómo el edificio gótico es el resultado manifiesto entre la voluntad de dos partes, la del promotor y del constructor, en el contexto escolástico. La interacción entre ambas figuras fue puesta de manifiesto por Wilhelm Worringer (1881-1965) en el Formprobleme der Gotik (1911) y Erwin Panofsky (1892-1968) en el Gothic Architecture and Scholasticism (1951). ${ }^{3}$

de Tortosa en un inventari de 1420. Anuario de Estudios Medievales, 1999, $\mathrm{n}^{\circ}$ 29, pp. 3-20.

${ }^{3}$ Worringer, Wilhelm. 1911. Formprobleme der Gotik. München: Piper Verlag. Panofsky, Erwin 1951. Gothic Architecture and Scholasticism. Pennsylvania: Archabbey Press 
La búsqueda de los principios de los cánones de la creación medieval se encuentra en parte en la cosmología del Timaeus de Platón (c.429-347 aC), como reconocía Francis Macdonald Cornford (18741943) en Plato's Cosmology. The Timaeus of Plato (1937). ${ }^{4}$ Por ello, uno de los puntos de contacto entre el estamento clerical y el artesanal se establece en el significado de la medida y proporción de la arquitectura.

Desde la óptica del mundo de las catedrales góticas, Otto von Simson (1912-1993) en The Gothic Cathedral: the origins of Gothic Architecture and the Medieval Concept of Order (1956), ${ }^{5}$ abordó la cuestión de las fuentes cultas, buscándolas en la Civitatis Dei, De Ordine y la Musica de San Agustín (354-420). Las completa con autores como Boecio (480-524), y la De consolatione philosophiae y la Musica, así como con los principales comentaristas de Platón. Entre ellos, Calcidio (f.350) con el Timaeus translatus commentarioque instructus, Marciano Capella (fol. 430) con el De Nuptiis Philologiae et Mercurii Comentarii y Macrobio (f.400), con el In Somnium Scipionis.

La renovada búsqueda de los cánones creativos en la geometría platónica del Timaeus, ha sido nuevamente planteada por Carmen Bonell $(1999)^{6}$ y completada por Nigel Hiscock (2000); la cual se expresa a través de los referentes de las Stromatesis de Clemente de Alejandría (c.150-c.215), el Hexaëmeron de Basilio el Grande (c.330-379) y De hominis opifico de Gregorio de Nisa (c.335-c.395). ${ }^{7}$ Esta revisión hace totalmente vigente la relación, directa o circunstancial, de dichas fuentes directas con el conocimiento de los promotores eclesiásticos de las catedrales góticas. Por otra parte, se incide en la necesidad creativa en el diseño gótico, que emana directamente de la geometría, planteada por Robert Bork (2011). ${ }^{8}$ Se intenta así establecer en esta investigación la relación entre el estamento clerical y el artesanal en la catedral gótica de Tortosa.

4 Cronford, F.M. 1937. Plato's Cosmology. The Timaeus of Plato. London: Kegan Paul, Trench, Trubner \& Co.

5 Simson, O.G. 1956. The Gothic Cathedral: the origins of Gothic Architecture and the Medieval Concept of Order (New York and Evanston: Harper\&Row.

6 Bonell, C. 1999. La divina proporción. Las formas geométricas. Barcelona: Universitat Politécnica de Catalunya. Capítulo IV, La acción del Demiurgo, pp 83-109.

${ }^{7}$ Hiscock, N. 2000. The Wise Master Builder. Platonic Geoemtry in Plans of Medieval Abbeys and Cathedrals. Aldershot y Brookfield, Vermont: Ashgate. Especialmente el capítulo, Clasical and early Cristian sources, pp, 43-95.

8 Bork, R. 2011. The Geometry of Creation: Architectural Drawing and the Dynamics of gothic Design. Farnham: Ashgate Press. 


\section{LAS NUEVAS NECESIDADES DE LA ARQUITECTURA GÓTICA}

La nueva catedral gótica de Tortosa sustituyó a la seo románica, ecclesiam vetulam, que había sido consagrada en $1178 .^{9}$ Las tipologías de la arquitectura gótica del siglo XIV se adaptarán a la nueva liturgia del Prochiron, vulgo rationale divinorum officiorum (1291) de Guillermo de Durando (1230-1296). Esta liturgia se integró en la catedral de Tortosa, a través del conocimiento directo de sus canónigos. Muestra de ello son algunos documentos de su biblioteca capitular: el códice ACTo n58, (f. XIII), y los incunables de la edición de Roma (1477) (ACTo n²58) y de Venecia (1482) (ACTo $n^{\circ} 290$ ). El Prochiron definirá la correspondencia entre la ecclesia materialis y la ecclesia spiritualis, ${ }^{10}$ sustituyendo la visión alegórica de la liturgia de la Gemma animae (c.1120) de Honorio de Autun (1080-c.1153). ${ }^{11}$

La nueva liturgia busca el uso correcto y una caracterización de la imaginería cristiana en el ambiente litúrgico, en lo que se define como la ecclesia materialis. Esta ecclesia se visualiza por el hecho constructivo y escenográfico del espacio arquitectónico que engendra la catedral. ${ }^{12}$ Todo ello responde a la voluntad de crear y contener una ecclesia spiritualis. Esta ecclesia puede estar representada en los contenidos teológicos y filosóficos depositados en la biblioteca de su Archivo Capitular. La construcción de la catedral dependía de la habilidad de los maestros constructores, que tienen una formación y unos conocimientos prácticos en términos medievales. Por otra parte, existe la formación teórica que disponían los promotores de la catedral. Unos conocimientos que se inducían de manera más o menos directa, a través del Capítulo y el obispo, a los constructores de las catedrales. (Figura 2).

${ }^{9}$ Almuni; Lluis, 2000. Sancta Maria Dertosae. Catedral de Tortosa. Guia Històrica i Descriptiva. Tortosa: Capítol Catedral de Santa Maria, pp. 30.

10 Sebastián S. 1994. Mensaje Simbólico del Arte Medieval. Arquitectura, Liturgia e Iconografía. Madrid: Ediciones Encuentro, pp. 352-355.

11 Mambelli, F. 2004. "Il problema dell'immagine nei commentari allegorici sulla liturgia: Dalla Gemma Animae di Onorio d'Autun (1120 ca.) al Rationale divinorum officiorum di Durando di Mende (1286-1292)". Studi Medievali. Jun 2004, Vol.45 I.: 1, pp. 121-158.

${ }^{12}$ Van der Ploeg, K. 2003. "On the correct usage and characterization of Christian imagery within the liturgical milieu: Durandus of Mende's "'Rationale Divinorum Officiorum'" and the function of imagery in art". Speculum a Journal of Medieval Studies, Oct 2003, Vol. 78, I. 4, pp. 1287-1288. 
Figura 2

ÁBSIDE CATEDRAL TORTOSA (1383-1441)

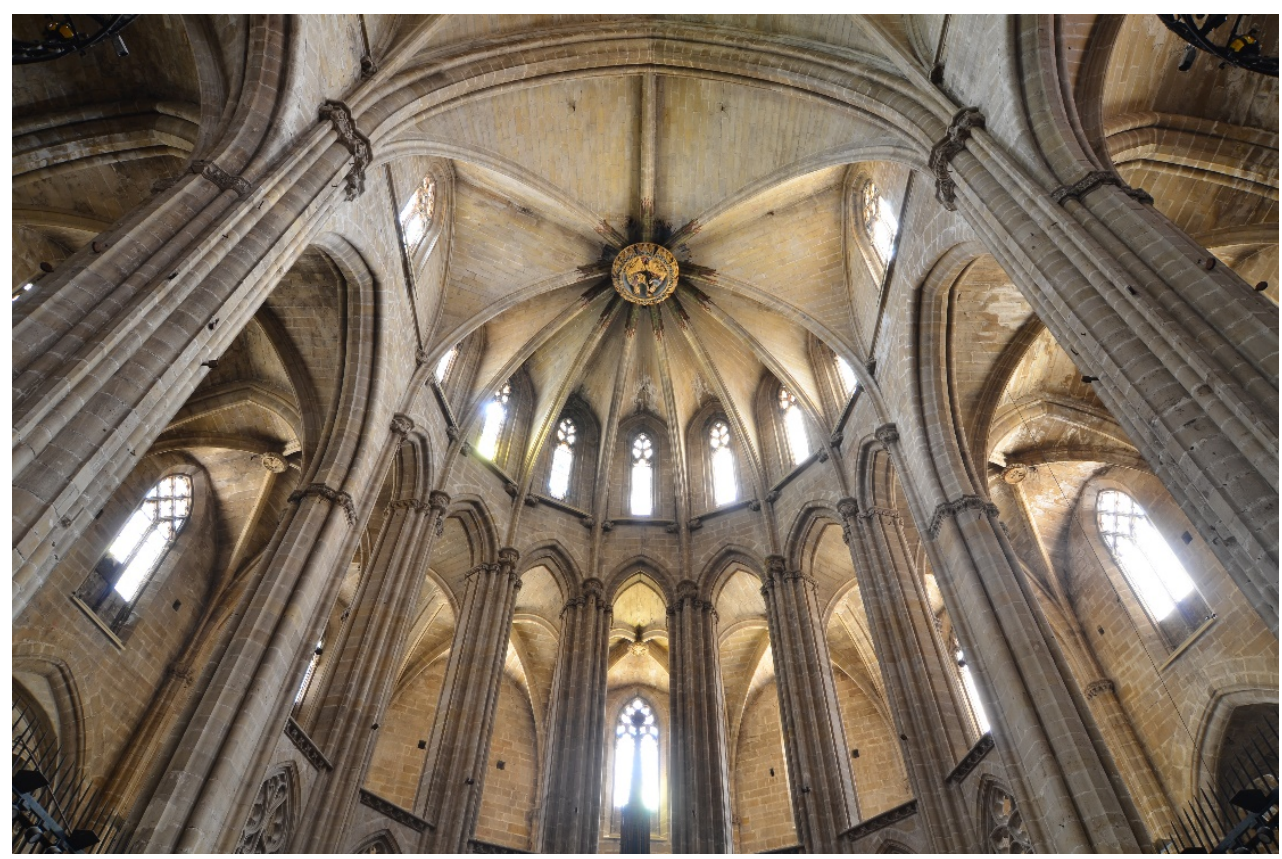

Cabe preguntarse cuáles son los límites de este conocimiento, y cuál es el trasvase de los saberes entre los eclesiásticos y los constructores de catedrales. Un ejemplo es el del canónigo de la Catedral de Notre-Dame de Noyon, Charles Bouvelles (1478-1567). ${ }^{13}$ Este matemático planteaba en la Geometrie en francoys. Cy commence le livre de l'art et science de geometrie avecques les figures sur chacune rigle (1511), ${ }^{14}$ que una figura tan importante para el simbolismo cristiano

${ }^{13}$ En el catalogo del Archivo Capitular de la Catedral de Tortosa (ACTo 300) aparece; Caroli Bovilli Samarobrini: Tractatus varii de rebus philosophicis et mathematicis. Ambianis, 1509-1510. Bayerri, 1962, pp. 473-474.Se trata de una recopilación de textos filosóficos y matemáticos del humanista publicados en Paris (1510). Tractatus varii de rebus philosophicis. La compilación de Tortosa, con carácter filosófico científico el; Liber de intellectu, Liber de sensu, Liber de nichilio, Ars oppositorum, Liber de generatione, Liber de Sapient, Liber de duodecim numeris, Epistole complures. La segunda dedicada a la matemàtica, números y figuras polígonales; Insup mathematicuopus quadripartitu, De Numenis perfectis, De Mathematicis Rosis, De Geoemtricis Corporibus, De Geometricis Suplementis. Se tracta del conocido com: Liber de intellectu, Liber de sensibus, Libellus de Nihilo, Ars oppositorum, Liber de generatione, Liber de Sapiente, Liber de duodecim numeris, Philosophicæ epistolæ, Liber de perfectis numeris, Libellus de Mathematicis rosis, Liber de mathematicis corporibus, Libellus de mathematicis supplementis, Paris, Henri Estienne, 1510.

${ }^{14}$ Bouvelles, Ch. 1511. Geometrie en francoys. Cy commence le livre de l'art et science de geometrie avecques les figures sur chacune rigle. Paris: Henri Estienne. La obra fué reeditada y ampliamente difundida, como Livre 
como el heptágono no aparecía en los Elementa de Euclides (c.325c.265 aC). ${ }^{15}$ Dentro de la formación teórica de la cultura cristiana medieval, y de los Padres de la Iglesia, el siete representaba la Creación. Los seis primeros días están dedicados al trabajo (Gèn.1,1) y el séptimo, es el que Dios descansó (Gèn.1,2). Así, muchos de los ábsides de catedrales góticas disponen de cabeceras heptagonales, con nueve capillas radiales. Por tanto, necesitan del recurso de la figura del heptágono para trazar las siete capillas radiales sobre la semicircunferencia del presbiterio. Charles Bouvelles (1478-1567) había publicado, en el Libellus de mathematicis supplementis (1509), ${ }^{16}$ un método para el trazado del heptágono, utilizando la altura del triangulo equilátero, o lo que es lo mismo, la distancia de la proyección por la mitad del radio. El método theorica, utilizado por Bouvelles, es mucho más complejo que el trazado del heptágono empleado por Antoni Guarc (c.1345-1380), ${ }^{17}$ para la sede de Tortosa. Éste, en su practica, utiliza la

singularis touchant l'art et pratique de Geometrie. Ediciones; Livre singulier et utile, touchant l'art praticque de geometrie,composé nouvellement en françoys, par maistre Charles de Bouvelles. Paris: S. de Colines, 1542. Geometrie practique, composée par... Charles de Bouelles, et nouvellement par luy reveue, augmentée et grandement enrichie. Paris: Regnaud Chaudière et Claude, 1547; (Paris:1551); (Paris: Cavellat 1555); (Paris: Marnef et Cavellat, 1566). Geometrie practique composée par... Charles de Boüelles,... avec un traicté des mesures geometriques, des hauteurs accessibles ou inaccessibles et de toutes choses pleines ou profondes... par M. Jean-Pierre de Mesmes... Plus l'art de mesurer toutes superficies rectilignes, tiré des Elemens d'Euclide, par M. Jean Des Merliers d'Amiens. Paris : Cavellat, 1605 y 1608.

${ }^{15}$ Bouvelles 1542, fol. 25v. Los Elementa traducidos por Adelardo de Bath (1075-1166) hacia 1142, aborda el trazado de los polígonos regulares en el Libro IV. pero no hace referencia alguna a la figura de heptágono, tampoco lo hace la sintaxis matemática del Almagesto de Ptolomeo (c.85-165), traducido por Gerardo de Cremona (1114-1187) hacia 1175. El trazado del heptágono mediante instrumentos geométricos, será refutado primero por Kepler (15711630), en su Harmonices Mundi, Libri V, en el, Primus Geometricus, De figurarum regularium, quae proportiones harmonicas pariunt, ortu, classibus, ordine et diferntiis, causa scientiae et deomonstraciones (1619), dentro de la a Propositio. Heptagonus et figurae ab eo ommes (LI.45). ) y posteriormente por Gauss (1777-1855), al final de sus Disquisitiones Arithmeticae (1801), (SeccióVII-Poposicions 361-366), quién sentenciará la conmensurabilidad del lado del heptágono.

${ }^{16}$ Bouvelles, Ch. 1510, Liber de intellectu, Liber de sensibus, Libellus de Nihilo, Ars oppositorum, Liber de generatione, Liber de Sapiente, Liber de duodecim numeris, Philosophicæ epistolæ, Liber de perfectis numeris, Libellus de Mathematicis rosis, Liber de mathematicis corporibus, Libellus de mathematicis supplementis. Paris: Henri Estienne. [Bouvelles 1510, Mas. Sup. fol. 192];

En el archivo Capitular de la catedral de Tortosa (ACTo), existe una pergamino $(917 \times 682 \mathrm{~mm})$, que representa la planta de una catedral, con la 
relación entre el ancho de la nave lateral (9 unidades), con la capilla radial (8 unidades), creando la relación metrológica de 9/8. ${ }^{18}$ (Figura 3).

\section{Figura 3}

PERGAMINO ANTONI GUARC (C.1345-1380). ACTo FÁBRICA 49
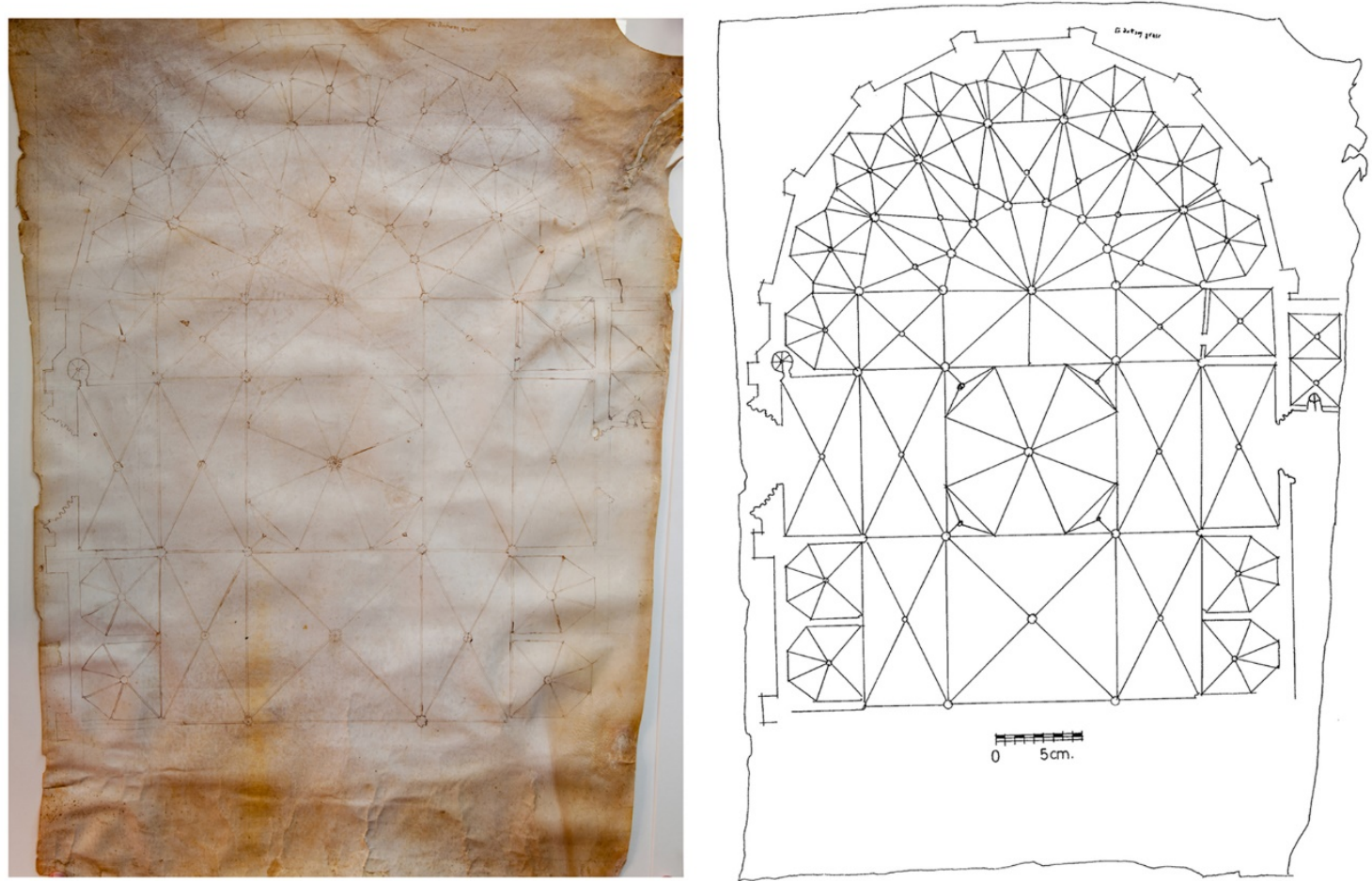

\section{LOS FUNDAMENTOS DEL ORDEN GÓTICO}

La idealización del orden de la arquitectura gótica, adopta los principios de los cánones de la creación establecidos en el Timaeus de Platón (c.429-347 aC). La cosmología neoplatónica recogida en el Timaeus había generado las geométricas básicas del gótico. Así es como define las formas más bellas, a las construidas a partir del triángulo rectángulo (Tim.53 cd), el cuadrado (Tim.53 d) y el triángulo equilátero (Tim.53 de). También las secuencias numéricas que imponen el 1, 2, 3,

anotación "En Antony Guarç". En el verso "Fábrica -N49-", "Mostra d’En Antony Guarç". A partir de las trazas del compàs es possible deducir la cosntrucción del heptágono utilizado en el despliegue de la planta.

18 Lluis; et.al, 2013. "Gothic construction and the traça of a heptagonal apse. The problem of the heptagon". Nexus Network Journal: Architecture and Mathematics. Vol. 15, I. 2 (2013), pp 325-348. 
4, 8, 9, 27 (Tim. 35-36). Estas figuras y números forman parte del sustrato proporcional de la música y de la arquitectura medieval. ${ }^{19}$

Desde la óptica de la construcción gótica, se reconocen los orígenes del orden de las catedrales en los desarrollos filosóficos de la Escuela de Chatres y Reims. Se otorga a estos fundamentos los orígenes de las fuentes patrísticas de San Agustín (354-420), y algunos textos de Boecio (480-524), pero será la filosofía neoplatónica de los principales comentaristas de Platón, Calcidio (f.350), Marciano Capella (fol. 430) y Macrobio (f.400), el principal conector con la tradición del Timeo. ${ }^{20}$

Este orden gótico, idealizado en la Escuela de Chartres, se realiza a través de la formación en las artes liberales, especialmente el quadrivium. La definición viene reconocida por San Agustín (354-420), en la Disciplinae Liberales intellectum Efferunt ad Divina del De Ordine (L. II.16). ${ }^{21}$ Estas definiciones van a aparecer coetáneamente en la biblioteca Capitular de Tortosa (ACTo 40). Así después de la guarda del fol. 91, con caligrafía del siglo XII, ${ }^{22}$ van a aparecer las definiciones de las ars. Las del trivium, grammatica, dialectica, retorica; son representadas por, Priscianus, Aristóteles y Tullius, mientras que las definiciones las del quadrivium, aparecen definidas;

Arithmetica: Omnia sub numero que possum discernere quero. Geometria: Corpora mensura claudo, data hec mihi cura. Musica: Dissona consio consors modulamine studio Astronomia: Astrorum iura monstro persigno futura Pitagora: Quid uirtus numerus docet hec qui nexus et ordo Millesius: Hec mensurandi doctrinam studet et usum. Euclyde: Musica cuncta ligat narrat discrimina uocat Ptholomeus: Hec docet astrorum leges loca tempora motus

${ }^{19}$ Platon. 1997. Dialogos VI. Filebo, Timeo, Critas. Madrid: Gredos, pp. 155-261

20 Simson, O.G. 1952. "The Gothic Cathedral: Design and Meaning". Journal of the Society of Architectural Historians, Vol. 11, No. 3 (Oct., 1952), pp. 6-16.

${ }^{21}$ Agustín de Hipona, 1994. Obras Completas San Agustín I. Escritos filósoficos $\left(1^{\circ}\right) .6$ ed. Madrid: Biblioteca Autores Cristianos. Del Orden, pp.594707.

22 Bayerri 1962, p. 180. 
Figura 4

ESCUELA DE CHARTRES. GUILLERMO DE CONQUES ACTo 144,

ACTo 80
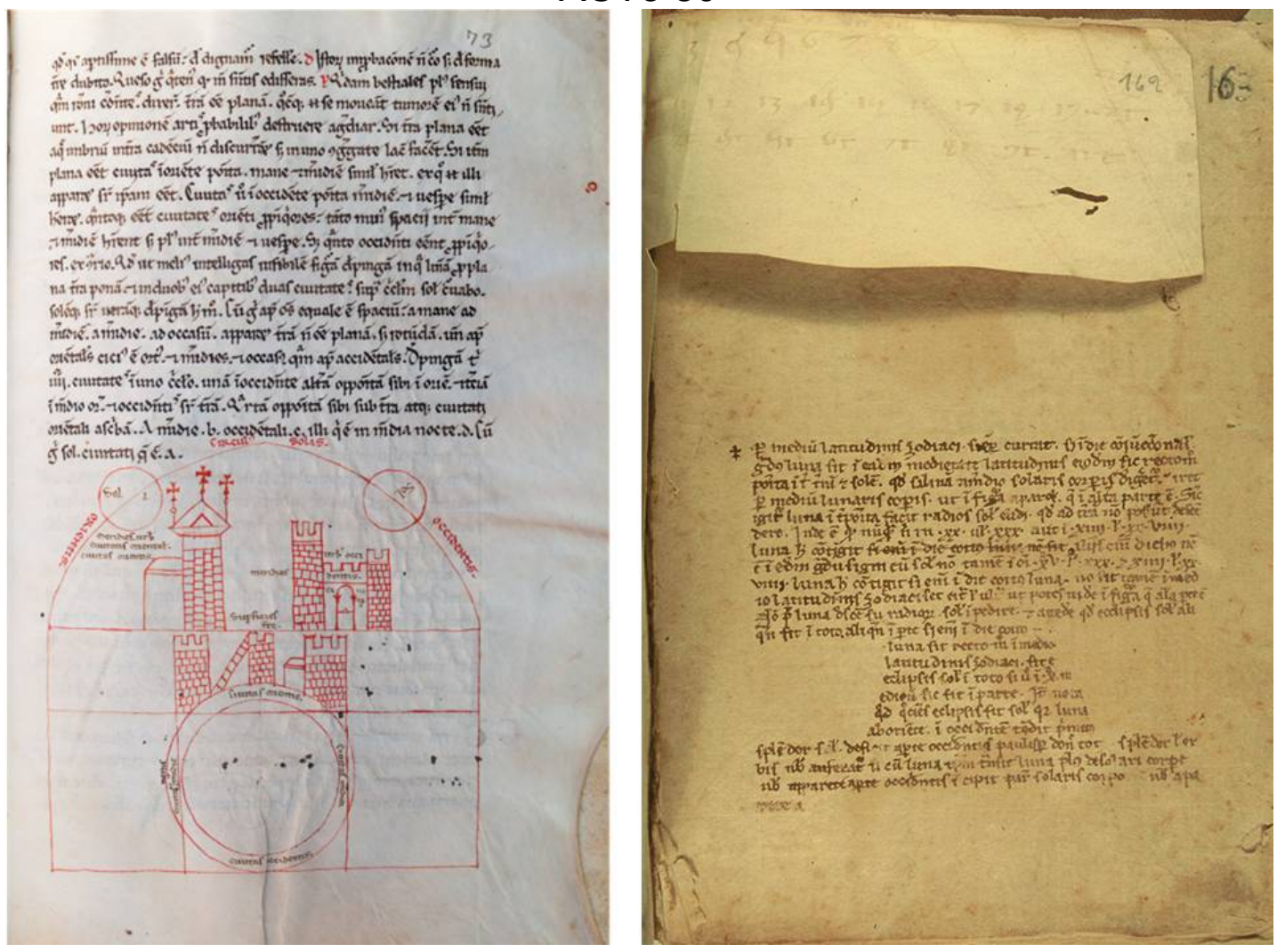

El ensalzamiento del quadrivium se hace patente en el Anticlaudiamus de Alain de Lille (c.1128-1202) del ACTo $\mathrm{n}^{\circ} 17$ (fol.1r73v). ${ }^{23}$ El códice describe el espectáculo de la corrupción humana, y la voluntad por parte de la Naturaleza de la construcción de un hombre perfecto, un ser que podrá regenerar el mundo. La Naturaleza necesitará la concurrencia de la Virtud para tal efecto. La joven Prudencia dudará del proyecto, al igual de la experimentada Razón, apareciendo luego la coordinación de la Concordia. La Prudencia será la encargada de construir un carro que los conducirá hasta el cielo en la búsqueda del alma de la nueva criatura. El proyecto lo realizan siete jóvenes, que representan las siete artes liberales, que son las que tienen los secretos de las actividades humanas.

En el Archivo Capitular de Tortosa, la Escuela de Chatres está presente con la figura de Guillermo de Conques (1080-1145) y su

${ }^{23}$ Incipit prolugus Anticlaudiani Alani de antiruffino. Referido por Bayerri, 1962, p. 153. Alain de Lille (c.1128-1202) es un autor destacado de la Escuela de Chartes. El códice del siglo XV, pertenece a la familia BNF. Lat.8300 de 1463. Bossuat, R. 1955. Alain de Lille. Anticlaudiamus. Texte critique avec une introduction et des tables publié par R. Bossuat. Paris: Libraire Philosophique J. Virin, pp. 55-198. 
enciclopedia del Dragmation Philosophiae. Existe un copia completa de la obra (ACTo $n^{\circ} 144$ fol.38r-90v) y un excepta en el (ACTo $n^{\circ} 144$, fol.163r-188v), ${ }^{24}$ con la parte dedicada a la astronomía (Figura 4). La Escuela de Reims está representada por la Geometria Incerti Auctoris de Gerberto de Aurillac (c. 940-1003), ACTo n80 (fol.159r I.1- 160 v I.27). ${ }^{25}$ Su geometría aborda cuestiones relacionadas con la medida indirecta de objetos cuyas bases no son accesibles. Las proposiciones de la apócrifa obra de Gerberto, tienen una metrología de proporcionalidad de base 12, donde se utilizan las relaciones: de igualdad 1/1, la 1/2 dupla o diapasón, la 2/3 sesquiáltera o diapente y la de $2 / 3$ sesquitércia o diatesarón. (Figura 5).

Figura 5

ESCUELA DE REIMS GEOMETRIA DE GERBERTO ACTo 80.
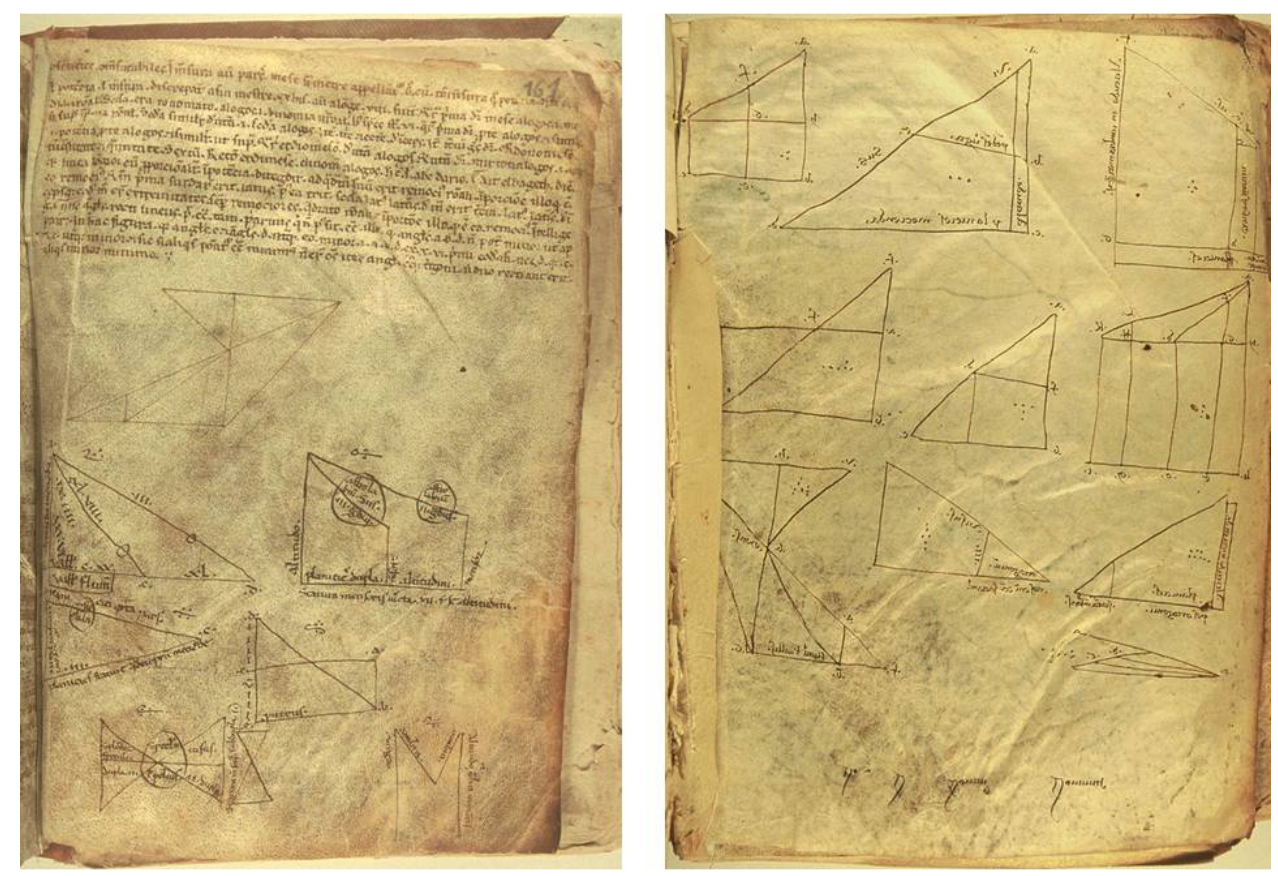

24 Ronca, Badia-Pujol (1997). Guillelmi de Conchis. Dragmaticon Philosophiae. Cura I. Ronca. Summa de Philosophia in Vulgari. Cura I. Badia, J. Pujol. Tvrnholti. Pypographi Brespols Editores Pontificii , pp. 1,273. En la codiologia de Ronca, son 8 las copias de los siglos XII-XIII. En la Península Ibérica, se conocen, la de Vic, ${ }^{\circ}{ }^{\circ} 18$, del siglo XIII, hoy en Halle, universidades und Landesbibliotheh, $Y C 8{ }^{a}$, la de la Biblioteca Nacional, Nada 28, copia ${ }^{\circ}$ 25 , de origen alemán (Johannes Vitez), y la de Salamanca del $n^{\circ} 46$ de la Biblioteca Universitaria, 1861 del siglo XV.

${ }^{25}$ Siglo XII. 20 proporciones del L.III y L.IV. Bubnov, N. 1899. Gerberti postea Silvestri II papae opera mathematica (972-1003). Berlin: Friedlände, pp. 317-330, pp. 336-338. 


\section{LA THEORICA DE LOS PROMOTORES DE LA CATEDRAL DE TORTOSA}

El estudio pormenorizado de alguno de los códices, más allá de la catalogación de Bayerri (1962), ha permitido identificar algunas fuentes a la que tenían acceso el estamento eclesiástico antes de la construcción de la catedral gótica (1345). Estos conocimientos han podido ser la base teórica de los promotores inducida a los constructores, de lo que hemos definido como orden gótico. Especialmente interés plantearán aquellos códices con fuentes patrísticas y neoplatónicas:

- El Civitatis Dei (ACTo n ${ }^{\circ} 20$ ) de San Agustín (354-420, completo con los XXII libros, es del siglo XII.

- La traducción del Timeo de de Calcidio (f.350), ACTo n 80 (146r-155v.14), con una parte de su Comentario (fol. 155v.15-66), del siglo XII.

- Un fragmento de la Geometría del De Nuptiis Philologiae et Mercurii de Marciano Capella (fol. 430) del Llibro VII de la Geometria, ACTo 80 (fol. 160 v.28- fol. 161r.5), del siglo XII.

- El Comentarii In Somnium Scipionis del ACTo 236 (fol.161v), excepto fol.39, de Macrobio (f.400), de siglo XIII, completo en sus dos libros.

- Otra parte del Comentario del Timeo de Calcidio (f.350), inserto en el ACTo 236 (fol.39), siglo XIII.

Figura 6

SAN AGUSTÍN. CIVITATIS DEI, ACTo 20
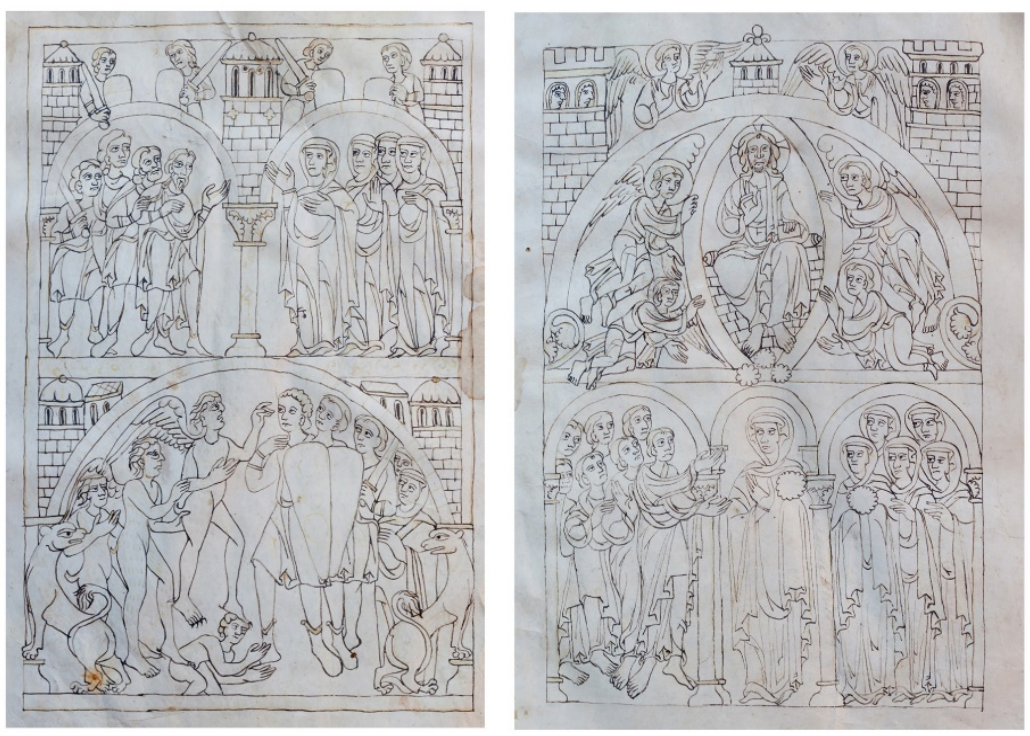


\section{El Civitatis Dei de San Agustín}

El Civitatis Dei (ACTo $n^{\circ} 20$ ) de San Agustín (354-420), hace referencia a la teoría numérica. En el libro XI (fol. 156r.-170v), dice que el seis es la perfección; así es el primer número que resulta de sus partes, $6=3+3+2+1(\mathrm{XI} .30)$. En cuanto al número 10, dice tener como divisores el $(1,2,5)$, mientras que el 12 , tiene los números $(6,4,3,2,1)(X I .30)$. El siete representa el séptimo día, que reconoce el reposo del Señor. Éste aparece como la adición de tres y cuatro $(7=4+3)$, (fol 168v-169v) (XI.31) ${ }^{26}$ En el libro XX (fol.333r-359r) recurre al número doce. Lo hace como parte del siete, pero también del tres y cuatro $(3 \times 4=12)$. El doce puede ser definido como el triple de cuatro y cuádruplo de tres (fol. 335r336v) (XX.5.3). Finalmente, aparece el mil, el número perfecto de la plenitud del tiempo. Este número se construye a partir de una figura cuadrada, que es plana, y que al darle altura, se convierte en cúbica. El mil resulta de del cuadrado $10 \times 10$, que al multiplicarlo por 10 , se convierte en mil. (fol. 337v-338v) (XX.7.2) (Figura 6). ${ }^{27}$

\section{Comentario del Timeo de Calcidio}

En el ACTo $\mathrm{n}^{\circ}$ 80, aparece la traducción del Timeo de Platón realizada por Calcidio (f.350) (146r-155v.14), acompañada por una pequeña parte de su Comentario al Timeo, ACTo $n^{\circ} 80$ (155v.15-66). ${ }^{28}$ Encontramos el inicio de la traducción del Timeo en el (fol.146r.1) Socrates in exortationibus suis virtutem... [5 Waz] hasta el (fol.152v.3) nancisceretur imaginem. Liber Platonis Timaeus explicit. [32 Waz]. A continuación, la Parte II del Timeo de Platón desde el (fol.152v.4), Et iam fere cuncta prouenerat... [33 Waz] hasta (fol.155v.14) uias peragraueritis, neque incognito et ex leui admonitione perspicuo [69Wz] (fol.115v.15 [...] liber explicit. ${ }^{29}$ Finalmente, el Comentario del Timeo entre el

${ }^{26}$ Agustín de Hipona (2000). Obras Completas de San Agustín XVI. La Ciudad de Dios $\left(1^{\circ}\right)$. Madrid: Biblioteca Autores Cristianos . Libro (XI.30), pp. 742-743,

${ }^{27}$ Agustín de Hipona (2001). Obras Completas de San Agustín XVI. La Ciudad de Dios $\left(2^{\circ}\right)$. Madrid: Biblioteca Autores Cristianos. (XX.5.3) 644, (XX.7.2) 655.

${ }^{28}$ En la catalogación de Bayerri aparece como ACTo 80. IV.- Platon, De Republica (Extracto de los libr. I y II).

${ }^{29}$ Edición de referencia; Waszink, J.H. 1975. Plato Latinus. IV. Timaeus, a Calcidio translatus commentarioque instructus, edit J.H. Waszink, editio altera. Londinnii, Leidae: En aedibus Instituti Warburgiani. La de, Mulliachus, Fr. 1867, Fragmenta Philosophorum Graecorum. Volumen II. Pythagoreos, Sophistas, Cynicos et Chalcidii in priorem Timaei Platonici partem comentarios continens. Paris: Editore Ambrosio Firmin Didot. pp. 147-181. La de Moreschini, 
(fol.115v.16), [Quis igitur] primae portionis numerous... y el (fol.115v.66), qui sunt in formula. Sic Calcidius. En el códice aparece un solo Comentario, la Descriptio tertia, quae est armónica, iuxta epogdoam ratioen modulans utranque symphoniam diatessaron et diapente (XLIX), acompañado de [tab.9]. La figura detalla la explicación de la proporcionalidad de las modulaciones numéricas, diatesarón y diapente (Figura 7). ${ }^{30}$

Figura7

COMENTARIO DEL TIMEO DE CALCIDIO ACTO Nº 80
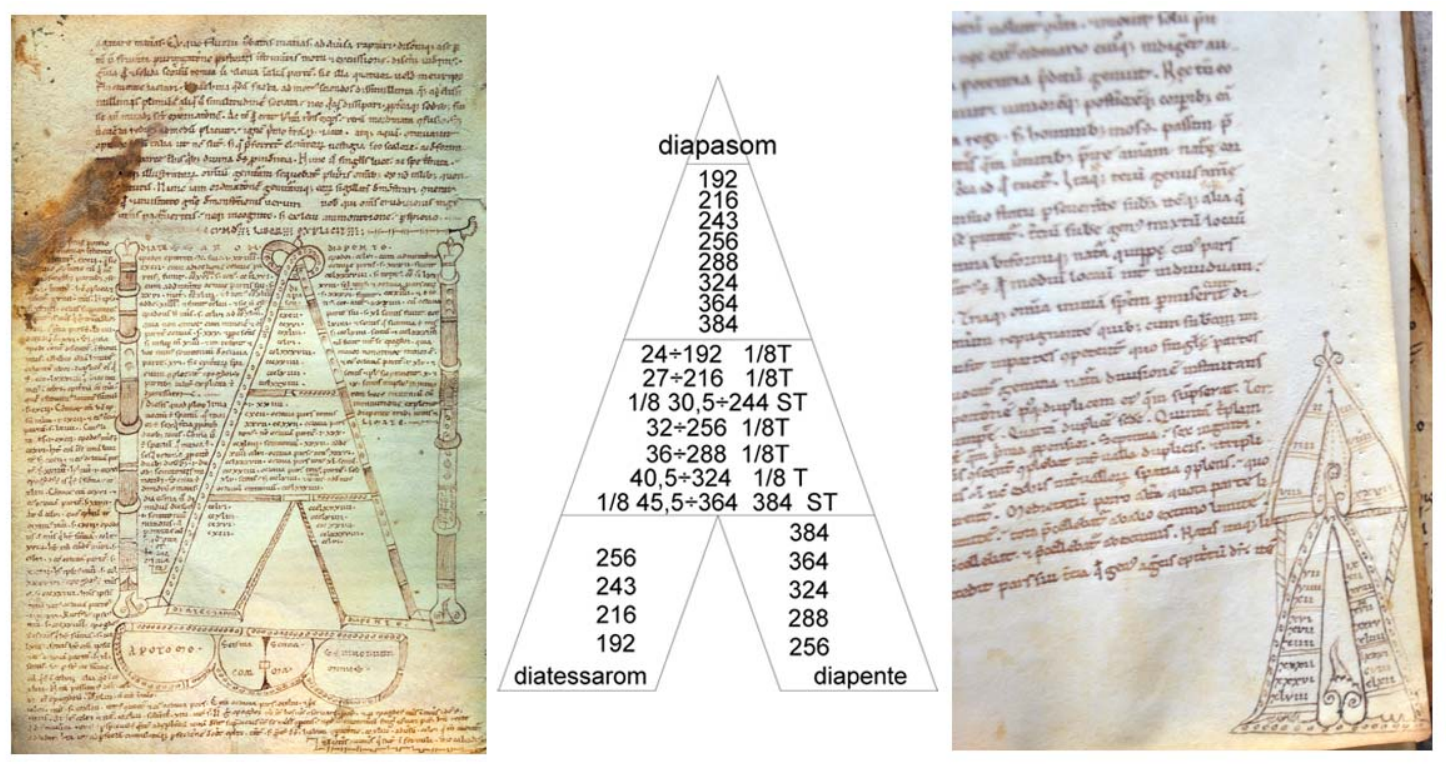

Una de las características del códice es la figura inserta entre el (fol.150.1) cuncta intra suum ambitum [25 Wz], y el (fol.150r.41) a Graecis epitritum dicitur [28Wz], en el margen derecho (fol150r.20150v.16). La figura viene a explicar el pasaje dedicado a la generación de las proporciones de los números [27Wz-28Wz]. De esta manera, se generan según la traducción de Calcidio, los números; $1,2(2=2 \times 1), 3$ $(3=2+1 / 2 \times 2), 4(4=2 \times 2), 9(9=3 \times 3), 8(8=1+7), 27(27=27 \times 1)$. En los intervalos define: la parte más su medio $(1+1 / 2)$; la parte y su tercio $(1+1 / 3)$, que llama epítrito; la parte y su octava $(1+1 / 8)$, que llama epogdo. Define el duplo, triple y cuádruplo, así como de la relación entre (243:256).

La figura que acompaña a la traducción del Timeo forma parte, en realidad, de los Comentarios del Timeo. Así resume, en una misma figura, el comentario (XXXII), [tab.7] y el (XLI) [tab.8]. El primero está dedicado al origen del alma con los números $1,2,4,8$ y 1, 3, 9, 27. El

C. 2003. Calcidius. Commentario al Timeo di Platone. Milano: Bonpiani. II Pensiero Occidentale. pp. 4-109.

${ }^{30}$ Waszink 1975; Mulliachus 1867, 192; Moreschini 2003, 204-207. 
otro, a las modulaciones armónicas con las series: $6,8,9,12,16,18,24$, $32,36,48$ y las $6,9,12,18,27,36,54,81,108,162$.

Una parte de la geometría de Marciano Capella

El fragmento del Libro VII de la Geometría de Capella, De Nuptiis Philologiae et Mercurio, comprende desde Ergasticis Schematibus [715] hasta Ex his aloge XIII fiunt, quarum prima dicitur Mese Alogos [720] (fol.160v.28-fol.161r.5), ${ }^{31}$ este códice no aparece en la catalogación de Leonardi (1959-1960). ${ }^{32}$

Define los géneros de las figuras planas: las ergásticas, que contienen los preceptos para formar cualquier figura; y las apodícticas, que aportan pruebas para las demostraciones. Las argumentaciones apodícticas se basan en métodos: systatikós, que permiten mediante las líneas establecer un triángulo; tmēmatikós, los que muestran con qué disposiciones cortamos las líneas; anágraphos, que definen como se puede unir y describir a una línea; el éngraphos plantea la manera de inscribir una figura en un círculo; perígraphos para circunscribir una figura en el círculo; parembolikós, polígonos equivalentes; proseuretikós dadas dos líneas desiguales, podemos encontrar la media proporcional.

Define también tres clases de ángulos: el regular, que es recto y que es siempre idéntico; el estrecho, que es agudo y variable; el ancho, que es obtuso y variable como el agudo, pero más ancho que el recto. Las líneas definidas son: isotếs, cuando dos líneas guardan proporción con una línea media de una longitud igual o doble; homólogos, cuando las líneas coinciden; análogos, cuando una es superada por otra en el doble de longitud, y supera también a una tercera en la misma proporción; álogos, o irracional, en la que no existe una coincidencia proporcional. Toda línea es rhētós, o es álogos. La primera línea es racional, ya que puede ser cotejada con una medida común, o cualquier cosa que compagine con ella. La segunda, en cambio, no coincide con ninguna, y no puede ser cotejada. Además, las líneas pueden clasificarse como las que coinciden entre sí, symmétrus y las que no coinciden,

${ }^{31}$ Edición de referencia Willis, J. 1983. Martianus Capella, edidit J. Willis. Leipzig: Teubner. En la de Ramelli, I. 2001. Marziano Capella. Le Nozze di Filologia e Mercurio. Testo latino a fronte. Introdizione, traduzione, comentario e appendici di Ilaria Ramelli. Milano: Bompiani. II pensiero occidentale, pp. 486491. En la de Ayuso, M. 2008. La terminología latina de la geometría en Marciano Capela. 2 vol. Tesis doctoral. Dirigida por el Dr. D. Antonio Moreno Hernández.Departamento de Filología Clásica Facultad de Filología. Universidad Nacional de Educación a Distancia. España, pp. 274-279.

${ }^{32}$ Leonardi (1959-60). C. Leonardi, I codici di Marziano Capella, Aevum XXXIII (1959), pp. 443-489; Aevum XXXIV (1960), pp. 1-99 y 411-524. Se conocen 240 manuscritos de Capella. 
asymmétrus. Por otra parte, dice que la longitud no es el único factor que hace conmensurables a las líneas. Por ello, es determinante también la potencia, a la que llama dynámei symmétroi. Las líneas iguales en medida se llaman mếkei symmétroi. Las que discrepan, sea en longitud o en potencia, son asymmétros. De estas líneas resultan otras trece irracionales.

\section{El Comentarii In Somnium Scipionis de Macrobio}

El Libro Primero aparece en el (fol.1-61v) Inter Platonis et Ciceronis. (I.1.1), hasta el (fol.35v.18) con las, disputationem sequentium reseruemus $(\mathrm{l}, 23,13){ }^{33}$ Él segundo en el (fol. 35v.19), Superiore comentario Eustathi (II,1,1), hasta el (fol. 61v.28), philosophiae comtinetur integritas $(\mathrm{II}, 17,17) .{ }^{34}$ Faltan los pasajes del $(\mathrm{I}, 5,7)$ hasta el $(I, 5,13)$ en el (fol. 6r). En el (fol. 6r.4) aparece la primera citación del sueño $(I, 5,2)$ con la noción de plenitud de la aritmética; Ac prima nobis tractandam, hasta el (fol. 12v.69), con la conclusión del excurso aritmológico $(1,6,83)$ singulos certa lege metitur. En el margen izquierdo del (fol. 6v 19-22) del capítulo correspondiente a las virtudes del número siete $(I, 6,3)$, aparece un esquema de las secuencias numéricas $(1,2,4$, $8)$ y $(1,3,9,27)$. Recuerda al dios creador del alma, con los números pares e impares, tomándolos como dobles y triples. Define las virtudes de los principales números $8,7,1,6,2,5$ y 3 , 4 en los capítulos $(I, 5,15$, I,6,23). Al ocho lo llama justicia; donde $8=7+1$, u $8=2 \times 4$, [ $8=2 \times 2 \times 2]$, o también $8=5+3$. Al siete lo considera pleno; $7=1+6,7=2+5,7=3+4$. Al uno, monás, que es masculino y femenino, a la vez par e impar. El número seis posee: el $1,1 / 3,1 / 6$; así $6 / 2=3,6 / 3=2,1 / 6=1$; de esta manera $1+2+3=6$. El dos es considerado como el primer número, diada, tras la mónada. El cinco es el Dios supremo, es la suma total del universo. El tres es el primer número, es un término medio para cohesionarlos. El cuatro es el primer número en obtener dos términos medios (Figura 8).

El Libro II forma parte del tratado de la música. Empieza con la armonía de las esferas $(I I, 1,1)$, finalizando en el capítulo, del por qué oímos esta música $(\mathrm{II}, 4,15)$ non capitat audium (fol.43r.4). Entre los (fol.46v-47v) aparecen los esquemas de los cinturones de la tierra, como las configuraciones celestes y de la tierra. En el folio (51bis) aparece una

${ }^{33}$ Edición de referencia Willis, J. 1970. Macrobius. Comentarii In Somnium Scipionis. Stugar-Leizpzig: B.G. Teubner. En la de ArmisenMarchetti. 2001. Macrobe. Comentaire au Songe de Scipion. Tome I, Livre I. Paris: Les Belles Letres, pp. 1-134. En la de Navarro, F. 2006, Macrobio. Comentario al Sueño de Escipión. Madrid: Editorial Gredos. pp. 125-319.

${ }^{34}$ Willis, J. 1970, Armisen-Marchetti, 2003. Macrobe. Comentaire au Songe de Scipion. Tome II, Livre II. pp. 1-86, Navarro, F. 2006, 321-449. 
figura con las definiciones de las proporciones diatesarón y diapente. El esquema explica las relaciones armónicas $(I I, 1,15)$. Este gráfico inserto en la obra de Macrobio, es un pasaje más próximo al Comentario del Timeo de Calcidio (XLIX) [Waszink 1975]. Define después las relaciones armónicas (II,1,14); el epítrito (3:4), el hemiolio (3:2), el duplo (2:1), el triple (3:1), el cuádruplo (4:1), y el epogdo (9:8) (fol.36v.23). De la relación epitetra nace el intervalo musical del dià tessàrōn, del hemiolio el intervalo dià pénte, del duplo el dià pason, el triple dià pason kaì dià pénte, de la cuádrupla la dis dià pason y del epogdo el tónos (II,1,15-20). Se completa el pasaje con la definición de semitono entre la relación (243:256) (II,1,15-22) a la que los pitagóricos Ilamaron díesis (fol.37r.13)

Figura 8

COMENTARII IN SOMNIUM SCIPIONIS ACTo 236 Fol. 51
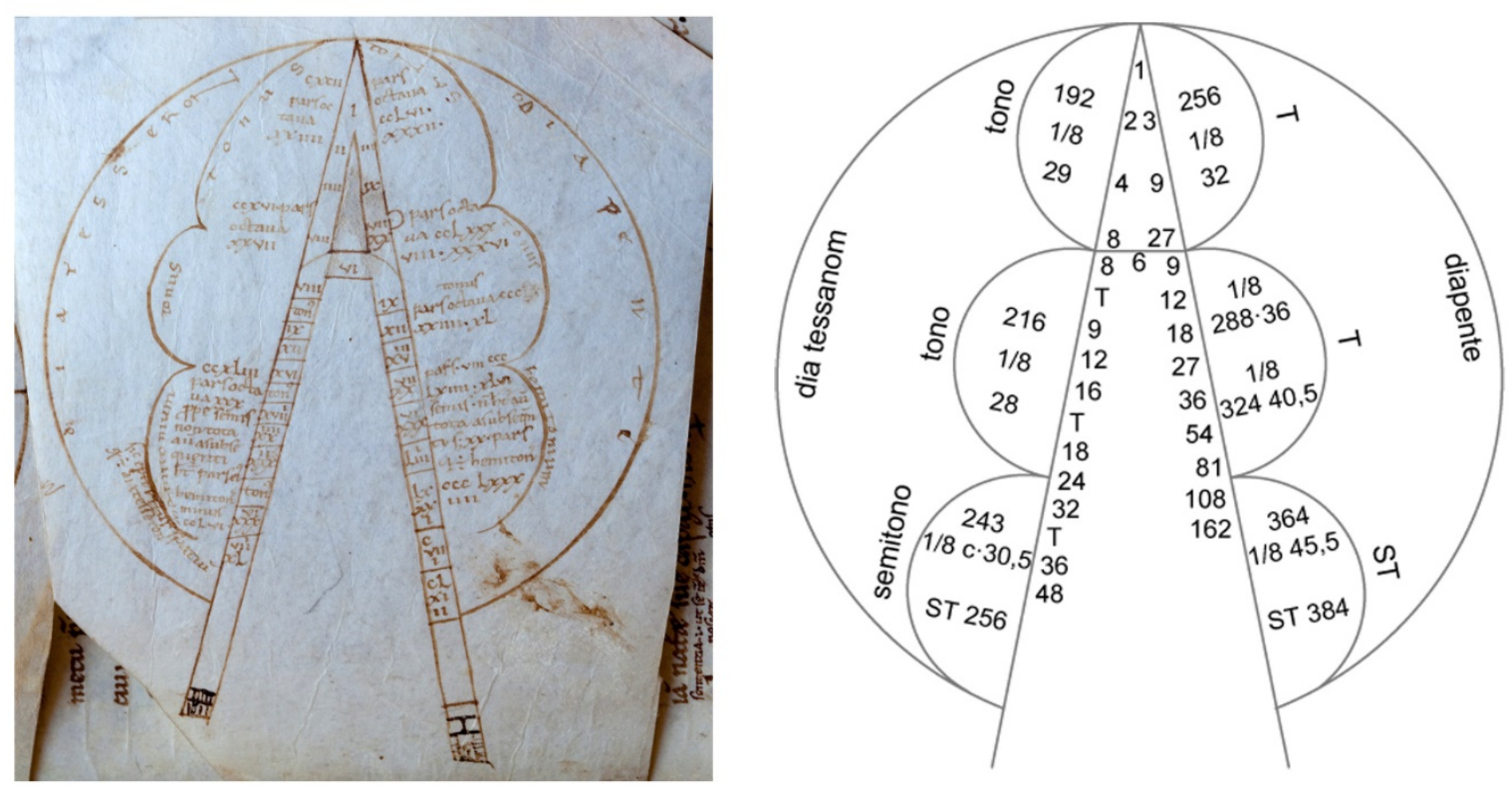

Una parte del Comentario del Timeo de Calcidio

Inserto en medio del Comentario del Sueño de Escipión (ACTo 126, fol.39), aparece una parte del Comentario del Timeo de Calcidio, de una mano diferente a la obra del ACTo 80. Se describen los pasajes; $D e$ modulatione siue Harmonica (XL, XLI, XLII), [tab.7], [tab.8]. ${ }^{35}$ Él Itaque figura similis eius quae paulo superius (XL), (ACTo 236, fol.39r.7), así como el (XLI), Quia VI numeris facit unum limitem et item XII (XLI), (ACTo 236, fol.39r.10). Está incompleto el pasaje XLII, conservando tan solo el inicio del texto [Haec eadem ratio], cortado después por la encuadernación.

${ }^{35}$ Waszink 1975; Mulliachus 1867, 189-190; Moreschini 2003, 186-191. 


\section{PARAMETRIZACIÓN DE LA MEDIADA EN LA CONSTRUCCIÓN DE LA CATEDRAL DE TORTOSA (1383-1441)}

Se plantea así, si la teoría numérica derivada de los códices del Archivo Capitular incide en la proporcionalidad de la construcción de la nueva fábrica. Para el estudio y parametrización de la medida en la catedral de Tortosa, se realizó una primera topografía informática entre (1995-2000). ${ }^{36}$ El modelo, suficientemente preciso para la planta del suelo de la catedral, carecía de todo valor para la determinación del plano superior de las bóvedas. Para ello, se realizó una segunda campaña en la que se obtuvo una modelización tridimensional del techo inferior de la catedral (2012). ${ }^{37}$ Se determinó que el patrón básico de las medidas de la catedral, el cual reiteradamente aparece en de los Llibres d'Obra (ACTo), es la cana de 8 palmos. La cana de la catedral tiene como medida $1,858 \mathrm{~m}$ y el palmo de 0,2323 $\mathrm{m}$. La medida de la cana de Tortosa estaba definida en el Libro IX, Rubrica 15.5 de las Consuetudines Dertosae (1272). ${ }^{38}$

Tras el inicio de la obra gótica (1345), se produjo una paralización de la fábrica, debido a la Peste (1347) y la Guerra de los dos Pedros (1356-1369). La obra se reanudó con la realización del cinturón de las nueve capillas radiales alrededor de la catedral románica, que continuaba en funcionamiento. Las nueve capillas radiales son de planta cuadrada, con bóvedas de crucería, y fueron construidas de forma correlativa, desde el evangelio a la epístola (1383-1424). La sección teórica de las

36 Lluis; Llorca, 2000. Pla Director Sancta Maria Dertosae. Tortosa: Bisbat de Tortosa. Departament Cultura Generalitat de Catalunya. Levantamiento manual, y compensados con unos puntos poligonales fijados mediante con una estación total SOKKIA, SET 3BII de 10cC de precisión angular en modo $2 \mathrm{cc}$ de resolución, dotada de compensador automático de doble eje y alcance máximo con un reflector de $2.500 \mathrm{~m}$, con precisión de $+/$ (3mm. $+3 \mathrm{ppm}$.).

${ }^{37}$ El modelo propuesto 3D, se construye mediante los datos combinados de una estación total y métodos fotogramétricos. La toma de datos se realizó con una Topcon Imaging Station 203, de precisión de 0,2 mm/1 mm $\pm(5 \mathrm{~mm})$, Cámaras (2) 1.3mp,Velocidad de imagen 1 - $10 \mathrm{fps}$, Exploración Max 20 pts/seg. Complementariamente con los del fotografiado exhaustivo con una cámara calibrada Nikon D7000+Tokina 12-24.

38 Consuetudines Dertosae (1272) (AHCTE cod.53, fol.256r), Llibre de les Costums Generals feutes de la insigne ciutat de Tortosa (1346) (FBMPM, fol.100r). El rey Felipe II (1527-1598) en las Cortes de Monzón (1585), Capitulo 89 unificación criterios métricos en Catalunya. Así los procuradores de la ciudad de Tortosa, bajo juramento remiten la documentación de la reducción de la cana de Tortosa a Barcelona, el 24 de julio de 1593. AHCTE, 387 (Comú II63) Registre. 
claves de las bóvedas, fue rematada a una altura de 45 palmos. ${ }^{39}$ En la segunda fase se construyen las nueve bóvedas de crucería del deambulatorio (1424-1435). Dos son de planta cuadrada, y siete son de planta trapezoidal, siendo cubiertas con un despliegue teórico a 72 palmos de altura. A diferencia de las capillas radiales, estas bóvedas fueron construidas simétricamente, cubriéndose a la vez las del lado de la epístola y las del evangelio. Finalmente, se cerró el presbiterio (14351441), con una clave de 10 palmos de diámetro, situado exactamente a 100 palmos de altura. ${ }^{40}$ La sección de las capillas radiales (1383-1424) tiene una relación de 9/5, mientras que en el deambulatorio (1424-1435) y en el presbiterio (1435-1441) pasa a tener proporción de 9/6. (Figura 9).

Figura 9

PLANTA CATEDRAL SANTA MARÍA TORTOSA

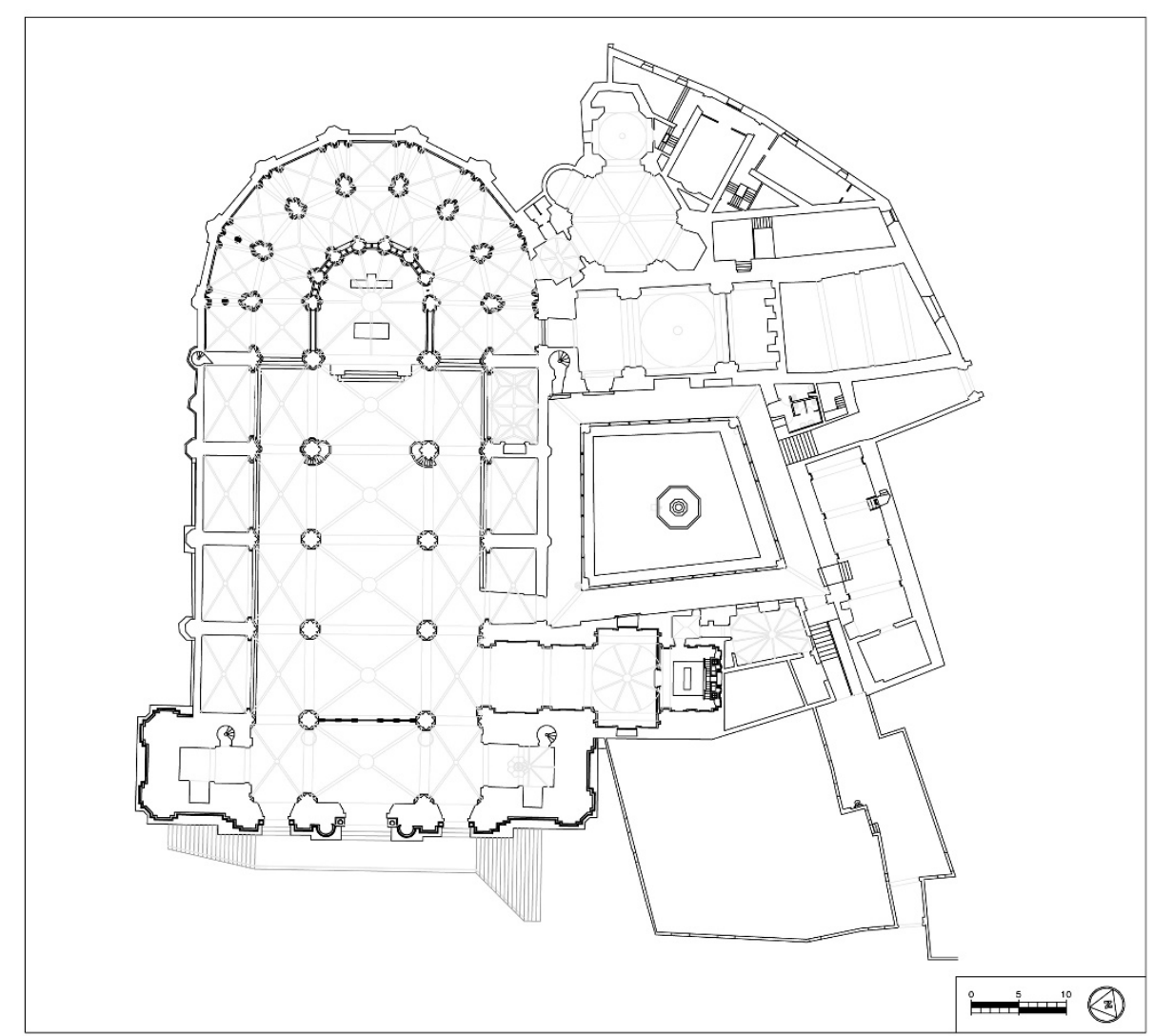

De esta manera la capilla es la unidad, nomada, es el elemento básico de la estructura de la nueva catedral gótica. La proliferación de las

${ }^{39}$ Lluis, J. 2009. "Evolución constructiva de los pilares de una girola gótica. El concepto de homogeneidad del material versus resistencia". En: Actas del Sexto Congreso Nacional Historia de la Construcción. Valencia. 2124 de octubre 2009. Madrid: Instituto Juan de Herrera, pp. 733-743.

40 Lluis; Almuni, 2011. "La clave de la clau. El cierre constructivo del presbiterio gótico". En: Actas del Séptimo Congreso Nacional Historia de la Construcción. Santiago de Compostela. 26-29 de octubre 2011. Madrid: Instituto Juan de Herrera, pp. 753-761. 
capillas laterales y radiales, es consecuencia directa de la nueva liturgia del Prochiron del obispo de Mende.

Esta tipología fue ensayada en las catedrales del Sur de Francia, caso de Clermont-Ferrand o Narbona, y exportadas a Catalunya a través de Girona. El Capítulo de la catedral de Girona, precisa en el contrato de obras con el magister operis para la construcción de la catedral, que el programa de su ábside disponga de nueve capillas radiales (1312). ${ }^{41}$

Figura 10

PRESBITERIO CATEDRAL SANTA MARÍA TORTOSA

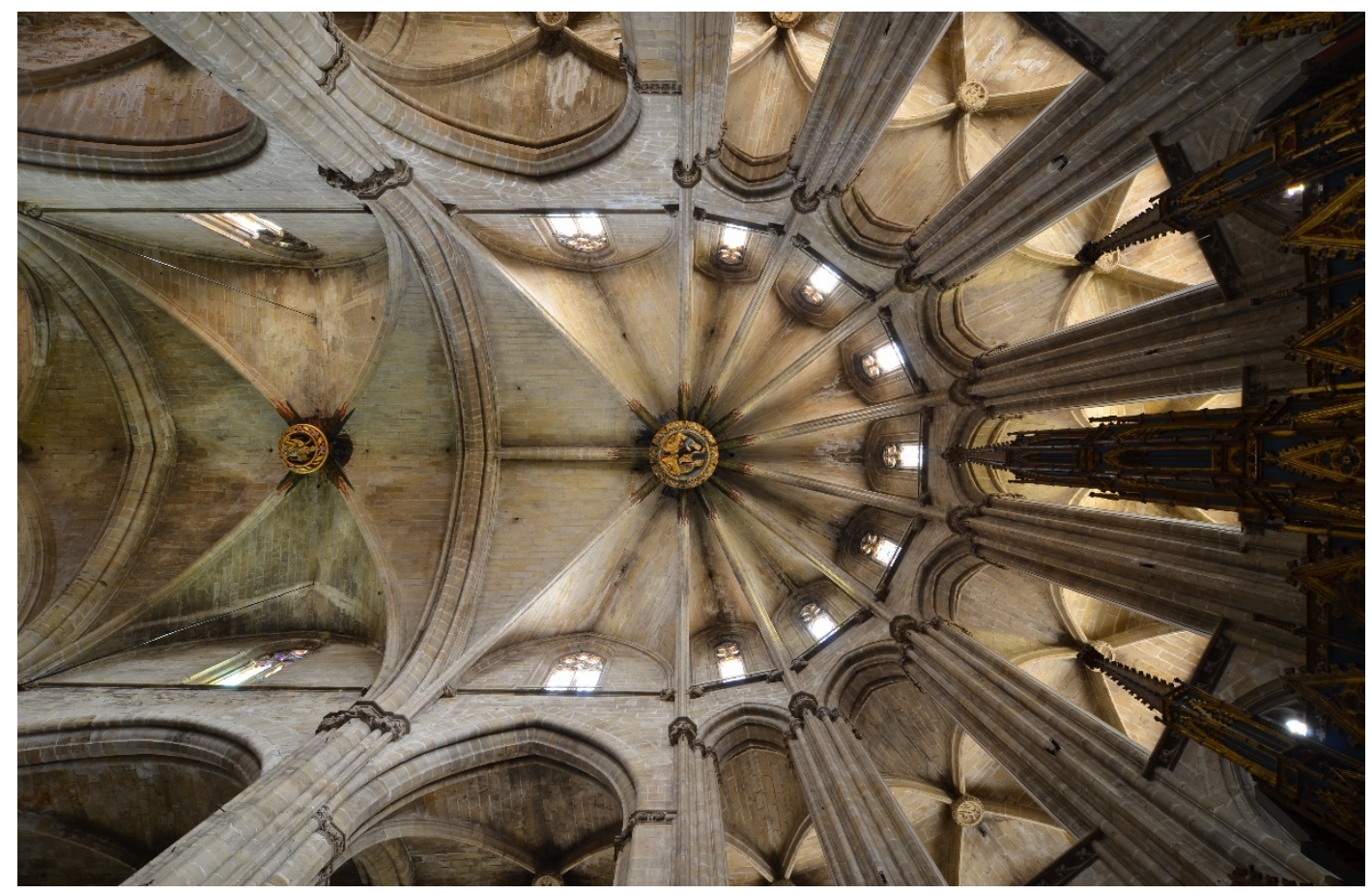

La cabecera de la catedral tiene unas proporciones metrológicas de: 150 palmos de ancho, 100 de fondo, 100 de altura. Los ejes de los pilares de las capillas radiales equidistan 24 palmos, lo que son 3 canas de Tortosa. Las capillas radiales, de planta cuadrada, miden 21×21 palmos. La sección del ábside tiene una altura de 45 palmos en las capillas radiales, 72 palmos en la girola y 100 palmos en el presbiterio, con la clave mayor de 10 palmos de diámetro. Todo un alarde de métrica de base aritmética y geométrica que se despliega como si fuera una

41 Street, G.E. 1865. Some account of gothic architecture in Spain. London: John Murray, Albemarle Street, pp 318, 339. Capitulum Gerundense more solito congregatum statuit, voluit et ordinvit, quod caput ipsius ecclesiae de novo construeretur et hadificaretur, et circun circa ipsum caput, novem capellae fierunt et in dormitorio veteri, fierit sacristia... Una traducción en Freixas, P. (et. alt.). 2000. La catedral de Girona. Redescobrir la Seu Romànica. Girona: Ajuntament de Girona, pág. 31. 
secuencia de un gran ábaco. Los canónigos de la catedral de Tortosa encargaron, al magister operis una catedral con una unidad básica, la de la capilla radial. A ésta unidad, le asignaron la medida de 3 canas, que son 24 palmos. A partir de éste patrón, todo se despliega de forma automática según un orden preestablecido (Figura 10).

\section{LA TEÓRICA VERSUS LA PRÁCTICA EN LA CATEDRAL DE TORTOSA}

El análisis de las medidas de la cabecera gótica permite establecer que éstas se rigen por un determinado orden. Este concepto de proporcionalidad entre las partes de la arquitectura, emana como un aspecto derivado de la ciencia medieval. El concepto de este conocimiento de proporcionalidad, se difundió en la Europa gótica a través del De Scientiis de Domingo de Gundisalvo (fl. 1150). Su precedente es el Catálogo de las ciencias de al-Fārābī (c.870-950). La proporcionalidad deriva del concepto filosófico medieval de la ciencia matemática, la llamada sciencia doctrinali. Dice al-Fārābī que la matemática es una de las cinco ciencias que se conocen. Así comprende las disciplinas de; la aritmética, la geometría, la óptica, la astronomía, la matemática, la música, la ciencia de los pesos y la ingeniería. Estos conceptos están relacionados, de forma más o menos directa, con los aspectos constructivos. Entre las ars destacan la Aritmética y la Geometría, de cuyas bases y principios, dice al-Fārābī, derivan las demás. En la definición de aritmética y geometría, distingue entre lo que define como ciencia theorica y practica. Gundisalvo utilizará estos mismos términos en el capitulo tercero De Scientiis, divulgados en el Speculum Doctrinale de Vicente de Beauvais (c.1194-1264) en $^{42}$ el mundo de las catedrales. La dualidad theorica y la practica impregnará la definición de las ars medievales. Estos conceptos están también latentes en la liturgia del Prochiron, vulgo rationale divinorum officiorum, (1291) de Guillermo de Durando (1230-1296). La catedral medieval ecclesia materialis visualiza el hecho constructivo de la fábrica, acogiendo en ella, la ecclesia spiritualis. La belleza de la construcción dependía de la habilidad de los maestros medievales, que con su practica que es activa, construyen sus elevadas bóvedas. Frente a ella, el conocimiento filosófico de los promotores de la catedral, con una ciencia theorica, cuya base es speculativa. Este conocimiento del promotor tiene un carácter

42 La edición de al-Fārābī de González Palencia, Á.1932, Alfarabi. Catálogo de las ciencias. Madrid: Facultad de Filosofia y Letras, pp. 39-53. La obra editada por Alonso, M. 1955. De Scientiis en Gundisalvo, D. De Scientiis. Compilación a base principalmente de la de Al-Farabi. Madrid: Consejo Superior de Investigaciones Científicas, pp. 85-112. La reconstrucción de la edición de Speculum Doctrinale de V. Beauvais de 1591, en apéndice I, pp.143-167. 
cosmológico y es inducido al constructor medieval a través de la metrología y la proporción de la arquitectura, construyendo así la Ciudad de Dios.

Por ello cabe especular entre las posibles influencias entre promotor y constructor. De aquí que la calve mayor de catedral de Tortosa mida 10 palmos de ancho y esté situada a 100 palmos de altura (Figura 11). Así, la clave, puede también definirse como la forma cubica del número mil de San Agustín (ACTo $n^{\circ} 20$ ), la plenitud del tiempo. La proporción sesquiáltera o diapente, de proporción (3/2), fija la sección de la catedral de Tortosa (9/6). De la misma manera, aparece la relación tonal (9/8) entre la capilla radial y el ancho de las naves en el proyecto de Antoni Guarc y en la obra construida. Estas proporciones utilizadas por los constructores en la fábrica, aparecen también en los códices de Calcidio (f.350), del ACTo $n^{\circ} 80$ (146r-155v), en el gráfico del fol.155 v. [tab.9], así como, en el fol. 39 del ACTo $n^{\circ} 236$. De la misma manera que en la obra de Macrobio (f.400), ACTo $n^{\circ} 236$, inspiran las proporciones de la sección del ábside; 150 palmos de ancho, 100 palmos de fondo y 100 palmos de altura, utilizando también la proporción (3/2).

Figura 11

CLAVE MAYOR DE LA CATEDRAL DE TORTOSA (1439-1441)

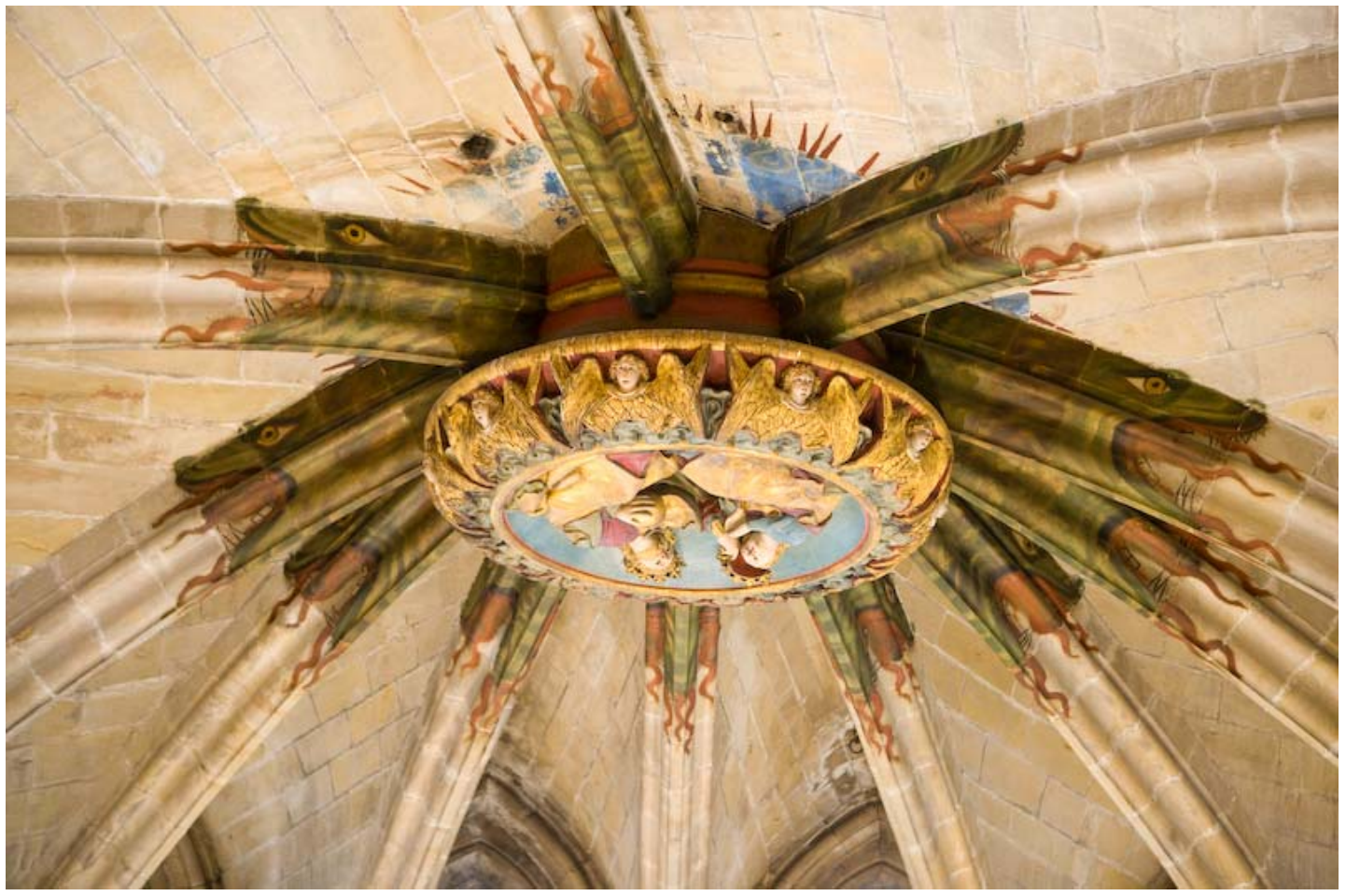

Si se analiza el fragmento del códice ACTo $n^{\circ} 80$, la geometría de Capella plantea dos tipos de líneas rhētós, y álogos. Tanto en el trazado del heptágono empleado por Guarç, como en el trazado del ábside, se utiliza la relación entre el ancho de la nave 9/8 con la capilla lateral. En 
términos de Capella es un trazado rhētós. Dado que se aplica la misma medida a las capillas del tramo recto del ábside y a las situadas en la cuerda del ábside. Con ello, la construcción se hace conmensurable y se iguala la medida de las capillas laterales y radiales. La relación de Guarç, (9/8), y la de la nave con las capillas, pueden ser interpretadas como la parte y su octava $(1+1 / 8)$. En los códices de Calcidio ACTo $n^{\circ} 80$ y Marcobio ATCo $n^{\circ} 236$ a esta proporción se le llama epogdo.

\section{CONCLUSIÓN. LA FÁBRICA GÓTICA DE LA CATEDRAL DE TORTOSA}

La idealización del orden medieval y el mundo de la creación del Timeo, y sus principales comentaristas, definidos por Cornford (1937), Simson (1956), Bonell (1999) y Hiscock (2000), aparecen explícitamente en la biblioteca capitular de la catedral de Tortosa. Es el caso de Agustín de Hipona, Calcidio, Macrobio y Capella. De ellos parte la conciencia y teoría proporcional que aparece implícita en la metrología de la construcción de la catedral gótica de Tortosa. En los códices, ACTo $n^{\circ} 20$ de San Agustín, el ACTo $n^{\circ} 80$ con Calcidio y Capella, y el ACTo $n^{\circ} 236$ de Macrobio, se reconoce la base de la teoría proporcional tanto del proyecto de la mostra d'En Antony Guarç, como de la traza de la fábrica gótica de la catedral de Tortosa. (Figura 12).

Más allá de la influencia litúrgica del Prochiron, vulgo rationale divinorum officiorum (1291), existe un orden general en la construcción de la fábrica gótica de base neoplatónica. Esta armonía tiene un claro sentido y despliegue metrológico, que va mucho más allá de la practica, activa del constructor medieval. El planteamiento cosmológico de la catedral parte de una theorica que es speculativa. En esta proposición ha de reconocerse la inducción de los conocimientos de los promotores eclesiásticos hacia los constructores de la catedral gótica.

Podría plantearse por el conocimiento de los textos clásicos y medievales del archivo capitular, que la catedral de Tortosa sería una obra canónica dentro del concepto de en The Gothic Cathedral: the origins of Gothic Architecture and the Medieval Concept of Order (1956) establecido por Otto von Simson (1912-1993). La comparación con otras catedrales españolas, a excepción del archivo de la catedral de Toledo, con una amplia colección de textos científicos, es difícil de establecer. La mayoría de las bibliotecas de las catedrales españolas fueron recogidas por Juan de Herrera (1530-1597) para la Biblioteca del Escorial para Felipe II (1527-1598). 
Figura 12

CATEDRAL DE SANTA MARIA DE TORTOSA

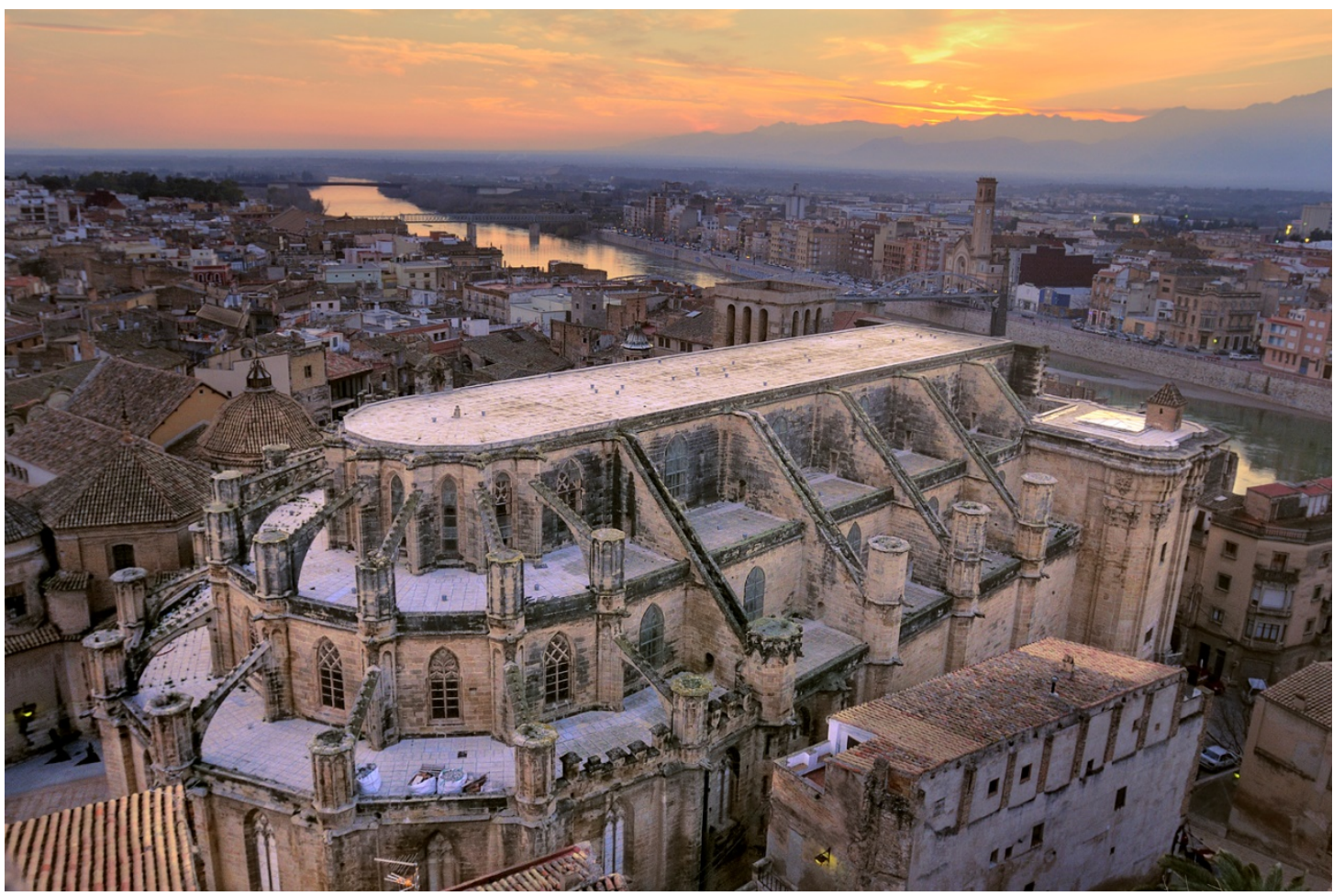

FUENTES DOCUMENTALES

ACTo. Archivo Capitular Tortosa

ACTE. Arxiu Comarcal Terres de l'Ebre

FBMPM. Fundación Bartolome March Palma Mallorca

\section{REFERENCIAS}

Agustín de Hipona, 1994. Obras Completas San Agustín I. Escritos filósoficos $\left(1^{\circ}\right) .6$ ed. Madrid: Biblioteca Autores Cristianos.

Agustín de Hipona, 2000. Obras Completas de San Agustín XVI. La Ciudad de Dios $\left(1^{\circ}\right)$. Madrid: Biblioteca Autores Cristianos.

Agustín de Hipona, 2001. Obras Completas de San Agustín XVI. La Ciudad de Dios $\left(2^{\circ}\right)$. Madrid: Biblioteca Autores Cristianos.

Almuni V; Llluis i Ginovart, J. 2000. Sancta Maria Dertosae. Catedral de Tortosa. Guia Històrica i Descriptiva. Tortosa: Capítol Catedral de Santa Maria. 
Alonso, M. 1955. Domingo Gundisalvo. De Scientiis. Compilación a base principalmente de la de Al-Farabi. Madrid: Consejo Superior de Investigaciones Científicas.

Armisen-Marchetti, 2001. Macrobe. Comentaire au Songe de Scipion. Tome I, Livre I. Paris: Les Belles Letres.

Armisen-Marchetti, 2003. Macrobe. Comentaire au Songe de Scipion. Tome II, Livre II. Paris: Les Belles Letres.

Ayuso, M. 2008. La terminología latina de la geometría en Marciano Capela. 2 vol. Tesis doctoral. Dirigida por el Dr. D. Antonio Moreno Hernández.Departamento de Filología Clásica Facultad de Filología. Universidad Nacional de Educación a Distancia. España.

Baiges, I. 1999. "Els manuscrits de la catedral de Tortosa en un inventari de 1420". Anuario de Estudios Medievales, 1999, n² 29, pp. 320.

Bayerri, E. 1962. Los Códices Medievales de la Catedral de Tortosa. Novísimo inventario descriptivo. Tortosa: Talleres Gráficos Algueró y Baiges.

Bonell, C. 1999. La divina proporción. Las formas geométricas. Barcelona: Universitat Politécnica de Catalunya.

Bork, R. 2011. The Geometry of Creation: Architectural Drawing and the Dynamics of gothic Design. Farnham: Ashgate Press.

Bossuat, R. 1955. Alain de Lille. Anticlaudiamus. Texte critique avec une introduction et des tables publié par R. Bossuat. Paris: Libraire Philosophique J. Virin.

Bouvelles, Ch. 1510. Liber de intellectu, Liber de sensibus, Libellus de Nihilo, Ars oppositorum, Liber de generatione, Liber de Sapiente, Liber de duodecim numeris, Philosophicæ epistolæ, Liber de perfectis numeris, Libellus de Mathematicis rosis, Liber de mathematicis corporibus, Libellus de mathematicis supplementis. Paris: Henri Estienne.

Bouvelles, Ch. 1511. Geometrie en francoys. Cy commence le livre de l'art et science de geometrie avecques les figures sur chacune rigle. Paris: Henri Estienne.

Bouvelles, Ch.1542. Livre singulier et utile, touchant l'art praticque de geometrie,composé nouvellement en françoys, par maistre Charles de Bouvelles. Paris: Simon de Colines. 
Bubnov, N. 1899. Gerberti postea Silvestri II papae opera mathematica (972-1003). Berlin: Friedlände

Cronford, F.M. 1937. Plato's Cosmology. The Timaeus of Plato. London: Kegan Paul, Trench, Trubner \& Co.

Freixas, P. (et. alt.), 2000. La catedral de Girona. Redescobrir la Seu Romànica. Girona: Ajuntament de Girona.

González, Á. 1954. Alfarabi 870-950. Catálogo de las ciencias. Madrid: Instituto Miguel Asin. CSIC.

Hiscock, N. 2000. The Wise Master Builder. Platonic Geoemtry in Plans of Medieval Abbeys and Cathedrals. Aldershot y Brookfield, Vermont: Ashgate.

Leonardi, C. 1959. "I codici di Marziano Capella". Aevum, XXXIII, 1959, pp. 1-99.

Leonardi, C. 1960) "I codici di Marziano Capella". Aevum , XXXI, 1960, pp. 411-524.

Lluis; Almuni, 2011. "La clave de la clau. El cierre constructivo del presbiterio gótico". En: Actas del Séptimo Congreso Nacional Historia de la Construcción. Santiago de Compostela. 26-29 de octubre 2011. Madrid: Instituto Juan de Herrera, pp. 753-761.

Lluis; et.alt. 2013. "Gothic construction and the traça of a heptagonal apse. The problem of the heptagon". Nexus Network Journal: Architecture and Mathematics. Vol. 15, I. 2 (2013), pp 325-348.

Lluis, J. 2009. "Evolución constructiva de los pilares de una girola gótica. El concepto de homogeneidad del material versus resistencia". En: Actas del Sexto Congreso Nacional Historia de la Construcción. Valencia. 21-24 de octubre 2009. Madrid: Instituto Juan de Herrera, pp. 733-743.

Lluis; Llorca, 2000. Pla Director Sancta Maria Dertosae. Tortosa: Bisbat de Tortosa. Departament Cultura Generalitat de Catalunya.

Mambelli, F. 2004. "Il problema dell'immagine nei commentari allegorici sulla liturgia: Dalla Gemma Animae di Onorio d'Autun (1120 ca.) al Rationale divinorum officiorum di Durando di Mende (1286-1292)". Studi Medievali. Jun 2004, Vol.45 I.: 1, pp. 121-158. 
Moreschini, C. 2003. Calcidius. Commentario al Timeo di Platone. Milano: Bonpiani. II Pensiero Occidentale.

Mulliachus, Fr. 1867. Fragmenta Philosophorum Graecorum. Volumen II. Pythagoreos, Sophistas, Cynicos et Chalcidii in priorem Timaei Platonici partem comentarios continens. Paris: Editore Ambrosio Firmin Didot.

Navarro, F. 2006. Macrobio. Comentario al Sueño de Escipión. Madrid: Editorial Gredos.

Platon, 1997. Dialogos VI. Filebo, Timeo, Critas. Madrid: Gredos.

Ramelli, I. 2001. Marziano Capella. Le Nozze di Filologia e Mercurio. Testo latino a fronte. Introdizione, traduzione, comentario e appendici di Ilaria Ramelli. Milano: Bompiani. II pensiero occidentale.

Ronca, Badia-Pujol. 1997. Guillelmi de Conchis. Dragmaticon Philosophiae. Cura I. Ronca. Summa de Philosophia in Vulgari. Cura I. Badia, J. Pujol. Tvrnholti. Pypographi Brespols Editores Pontificii.

Sebastián, S. 1994. Mensaje Simbólico del Arte Medieval. Arquitectura, Liturgia e Iconografía. Madrid: Ediciones Encuentro.

Simson, O.G. 1952. "The Gothic Cathedral: Design and Meaning". Journal of the Society of Architectural Historians, Vol. 11, No. 3 (Oct., 1952), pp. 6-16.

Simson, O.G. (1956). The Gothic Cathedral: the origins of Gothic Architecture and the Medieval Concept of Order. New York and Evanston: Harper\&Row.

Street, G.E. 1865. Some account of gothic architecture in Spain. London: John Murray, Albemarle Street.

Van der Ploeg, K. 2003. "On the correct usage and characterization of Christian imagery within the liturgical milieu: Durandus of Mende's "'Rationale Divinorum Officiorum"' and the function of imagery in art". Speculum a Journal of Medieval Studies, Oct 2003, Vol. 78, I. 4, pp. 1287-1288.

Waszink, J.H. 1975. Plato Latinus. IV. Timaeus, a Calcidio translatus commentarioque instructus, edit J.H. Waszink, editio altera, Londinnii, Leidae: En aedibus Instituti Warburgiani. 
Willis, J. 1970. Macrobius. Comentarii In Somnium Scipionis. Stugar-Leizpzig: B.G. Teubner.

Willis, J. 1983. Martianus Capella, edidit J. Willis. Leipzig: Teubner. 